\title{
Mulibrey Nanism
}

National Cancer Institute

\section{Source}

National Cancer Institute. Mulibrey Nanism. NCI Thesaurus. Code C84906.

An autosomal recessive inherited disorder caused by mutations in the TRIM37 gene. It is characterized by marked growth retardation and abnormalities in multiple organs including heart, liver, muscle, eyes, and brain. 